\title{
As representações femininas na obra Desonra de J.M. Coetzee
}

\author{
Las representaciones femeninas en la obra \\ Deshonor de J.M. Coetzee \\ The feminine representations in the work Disound J.M. Coetzee
}

\begin{abstract}
Alyne de Sousa Jardim 1
Resumo

Este trabalho pretende analisar a representação da condição feminina no romance sul-africano Desonra (1999) do escritor J.M. Coetzee. Traduzido por José Rubens Siqueira e publicado pela editora Companhia das Letras. O romance retrata como pano de fundo, o contexto social pós-colonial na África do Sul e a perda da hegemonia branca. Especificamente o período pós-apartheid marcado por intensos conflitos inter-raciais, sociopolíticos e o medo advindo de duras leis segregacionistas e longos anos de dominação colonial. Período em que foram ceifadas riquezas naturais, culturais, e até mesmo os corpos e vidas dos Sul Africanos. Metaforicamente, a dominação dos corpos femininos corresponde ao ato de colonizar a terra, possuí-la. A obra revisita os acontecimentos históricos, denuncia a violência contra povos nativos e as disputas por território por um viés pouco aprofundado pelas Literaturas pós-coloniais. Através da visão e ação do protagonista David Lurie enfatiza a mudança de posições sociais e inversão de poder que ocorreram nesse período. Explorou o medo sentido em relação à violência do revide histórico, sentiu-se deslocado sem alternativas. Coetzee trabalha todos estes tópicos literariamente para alcançar uma maior ressonância artística. A análise teórica do estudo partirá dos conceitos sobre dominação feminina discutidos por Bourdieu (2002), estudos pós-coloniais e resistência discutidos por Bonnici (2012), Fanon(1968) e Bhabha (2003). Esta abordagem promove um constante diálogo entre a cultura e o imperialismo para a compreensão de aspectos políticos e culturais em momentos de descolonização com o intuito de favorecer os marginalizados e oprimidos resgatando sua história, sua autonomia, além de promover uma abertura democrática do debate acadêmico.
\end{abstract}

Palavra-chave: África do Sul; Apartheid; Condição feminina; inversão de poder.

\section{Resumen}

Este trabajo pretende analizar la representación de la condición femenina en la novela sudafricana Deshonra (1999) del escritor J.M. Coetzee. Traducido por José Rubens Siqueira y publicado por Compañía de las Letras editorial. La novela retrata como telón de fondo, el contexto social post-colonial en Sudáfrica y la pérdida de la hegemonía blanca. Específicamente el período post-apartheid marcado por intensos conflictos interraciales, sociopolíticos y el miedo proveniente de duras leyes segregacionistas y largos años de dominación colonial. Período en que fueron diezmadas riquezas naturales, culturales, e incluso los cuerpos y vidas de los sudafricanos. Metafóricamente, la dominación de los cuerpos femeninos corresponde al acto de colonizar la tierra, poseerla. La obra revisita los acontecimientos históricos, denuncia la violencia contra pueblos nativos y las disputas por territorio por un sesgo poco profundizado por las Literaturas postcoloniales. A través de la visión y acción del protagonista David Lurie enfatiza el cambio de posiciones sociales e inversión de poder que ocurrieron en ese período. Exploró el miedo sentido en relación a la violencia de la revolución histórica, se sintió desplazado sin alternativas. Coetzee trabaja todos estos temas literalmente para alcanzar una mayor resonancia artística. El análisis teórico del estudio partirá de los conceptos sobre dominación femenina discutidos por Bourdieu (2002), estudios postcoloniales y resistencia discutidos por Bonnici (2012), Fanon (1968) y Bhabha (2003). Este enfoque promueve un constante diálogo entre la cultura y el imperialismo para la comprensión de aspectos políticos y

\footnotetext{
${ }^{1}$ Mestranda em Letras ; Universidade Federal do Tocantins -UFT, Porto Nacional, Brasil, alynejardim@yahoo.com.br
} 
culturales en momentos de descolonización con el objetivo de favorecer a los marginados y oprimidos rescatando su historia, su autonomía, además de promover una apertura democrática del debate académico.

Palabra clave: Apartheid; Condición feminina; inversión de poder; Sudáfrica.

\begin{abstract}
This work intends to analyze the representation of the feminine condition in the South African novel Desonra (1999) of the writer J.M. Coetzee. Translated by José Rubens Siqueira and published by Companhia das Letras. The novel portrays as a backdrop, the postcolonial social context in South Africa and the loss of white hegemony. Specifically the post-apartheid period marked by intense interracial, sociopolitical conflicts and fear arising from harsh segregationist laws and long years of colonial domination. A period in which natural, cultural, and even the lives and bodies of South Africans were harvested. Metaphorically, the domination of the female bodies corresponds to the act of colonizing the earth, possessing it. The book revisits historical events, denounces the violence against native peoples and the disputes over territory for a little biased in the postcolonial Literatures. Through the vision and action of the protagonist David Lurie emphasizes the change of social positions and inversion of power that occurred in that period. He explored the sense of fear in relation to the violence of historical revolt, he felt displaced without alternatives. Coetzee works all these topics literarily to achieve a greater artistic resonance. The theoretical analysis of the study will depart from the concepts of female domination discussed by Bourdieu (2002), postcolonial studies and resistance discussed by Bonnici (2012), Fanon (1968) and Bhabha (2003). This approach promotes a constant dialogue between culture and imperialism for the understanding of political and cultural aspects in moments of decolonization with the aim of favoring the marginalized and oppressed, rescuing their history, their autonomy, and promoting a democratic opening of academic debate.
\end{abstract}

Keyword: South Africa; Apartheid; Female condition; reversal of power.

\title{
1.Introdução
}

O presente artigo tem como proposta a análise do romance Desonra (1999) de John Maxwell Coetzee, africano da cidade do Cabo, nascido em 1940. Ganhou o Booker Prize por duas vezes; em 1983 com a obra: Vida e Época de Michael K. e Desonra, 1999. Além do prêmio Nobel de Literatura ainda com Desonra.

O romance foi traduzido para a Língua portuguesa por José Rubens Siqueira e publicado pela editora Companhia das Letras. O enredo de Desonra traz o contexto pósapartheid marcado pelos conflitos inter-raciais, a inversão social do homem branco que antes dominava e agora é subjugado. Assim como a representação da condição feminina, através da mulher branca que é violentada por homens negros e da mulher negra que é objetificada e violentada pelo homem branco. Segundo Bonnici no início da década de 60, Maxwell (1965) afirma categoricamente que o deslocamento e o exílio são um fator comum em toda a literatura pós-colonial em inglês. Acrescenta ainda:

A guerra civil pós-independência nos países africanos tem sido imputada às politicas de divisão provocadas pelos ex-poderosos coloniais, ao arremedo forçado das tribos e ao confinamento de populações dentro das fronteiras artificialmente delimitadas. (BONNICI, 2012, p. 223). 
Dessa forma, o intuito deste trabalho é discutir o contexto histórico e social, pósapartheid na África do Sul e as questões de gênero e dominação feminina. A partir dos conceitos de pós-colonialismo, resistência, expostos por Bhabha (2003) Bonicci (2009) e Fanon (1968) e discussão de gênero trazida por Bourdieu (2002) e ainda Beauvoir (2000).

No romance, o autor constrói personagens que retratam diversas relações entre classes, homens e mulheres, negros e brancos, como resultado de uma longa história de exploração e ressentimento. Apontando os sérios problemas políticos oriundos da segregação social, ocasionada pelo Apartheid, um regime de discriminação étnica, política e social que restringiu os direitos da população negra de 1940 até 1990, promovendo profundas disparidades sociais e econômicas que reverberam até os dias atuais.

\section{Território conquistado: uma metáfora do corpo feminino.}

O Romance Desonra de Coetzee traz um enredo impactante e ao mesmo tempo reflexivo para todos que se interessam ou desconhecem a realidade de países que foram colonizados. A trama inicia com o deslocamento do protagonista David Lurie, ex-professor do Departamento de Línguas modernas, de cinquenta e dois anos, desempregado, pois se envolveu com uma aluna e foi demitido. Sem perspectiva vai ao encontro de sua filha que mora em Kenton, no Cabo Leste. Ela é proprietária de uma fazenda no interior do país. Lucy é homoafetiva, e tenta subsistir cultivando a terra, para isso conta com ajuda de Petrus, um vizinho local.

A narrativa explora a condição e as representações da mulher na África do Sul, no contexto do pós-apartheid, particularmente da mulher branca que é ilustrada por Lucy filha do protagonista David Laurie. Demonstrando as relações entre as classes, os sexos, as raças, contrapondo assim, o passado de anos de exploração e submissão dos negros escravizados e explorados pelo poder colonial que persistiu da metade do século XVII até o fim do século XX. Esta imposição ocorreu devido à restrição de terra, água, gado, e exploração dos nativos que serviam como força de trabalho, criando assim uma estrutura econômica e política que os deixavam numa situação de inferioridade em relação ao colonizador.

O território africano, na visão dos europeus era privilegiado no que diz respeito aos recursos naturais, e posição geográfica que facilitava a colonização, por isso alguns descendentes de holandeses e ingleses se instalaram no país com a intenção de explorar, acumular riquezas e impor a superioridade de sua cultura. Como herança desta imposição tem 
se resquícios de leis que fomentaram o apartheid, evitando assim que negros e brancos se relacionassem e muito menos casassem. Segundo Dubow:

\footnotetext{
"As relações sexuais inter-raciais eram vistas como uma ameaça ao orgulho e à pureza racial, resultando no declínio da civilização branca... O medo da mistura racial diz respeito diretamente aos brancos, ansiosos por sua vulnerabilidade em face da vigorosa e viril massa de africanos" (DUBOW, 1995, p. 21).
}

Perfazendo assim uma analogia entre patriarcalismo/feminino e metrópole/colônia ou colonizador/colonizado. "uma mulher da colônia é uma metáfora da mulher como colônia". (DUPLESSIS, 1985, p. 45). Ao retratar a mulher europeia vulnerável ao homem negro, os africâneres se delegavam ao papel de protetores da mulher branca, visando estabelecer o controle e a ordem patriarcal.

Nesse sentido, a independência das mulheres brancas ameaçou as relações patriarcais e hegemonia da sociedade branca, pois se não fossem consideradas vulneráveis aos homens negros não poderiam ser protegidas e amparadas pelo homem branco. A mulher branca sofre uma dupla opressão em relação ao gênero e classe, além de representar o papel da mediadora entre a pureza racial da família e mantenedora do status social diferenciado.

É nesta perspectiva que abordaremos a personagem de Lucy, mulher branca, escolarizada, herdeira da cultura branca, filha de um professor universitário que subverte a construção do feminino, delicada, bonita; estabelecida pela hegemonia masculina. "Grande é uma palavra generosa para Lucy. Ela logo será definitivamente gorda. Abandonada, como acontece quando alguém se retira do campo do amor" (COETZEE, 1999, p.62). Um corpo deslocado, inicialmente por sua escolha sexual, e posteriormente por mudar-se para o interior da África do Sul, uma região com costumes, cultura e regras sociais diferentes.

A personagem vai contra as convenções culturais de masculino e feminino, luta para conseguir administrar a propriedade onde vive. Seu comportamento converge com o pensamento de Beauvoir (2000): "Não se nasce uma mulher, torna-se uma". A autora se contrapõe a visão reforçada pela ordem social que funciona como um sistema simbólico e ratifica a dominação masculina, pré-concebida pela divisão do trabalho inerente a cada um dos sexos, instrumentos e estruturas dos espaços que podem ocupar. "o mundo social constrói o corpo como realidade sexuada e como depositário de princípios de visão e de divisão sexualizantes" (BOURDIEU, 2002, p. 23).

A personagem Lucy, apesar de ter sido criada numa cultura que os negócios e a administração são atividades econômicas exercidas por homens e na maioria dos casos brancos. Tenta de todas as maneiras possíveis obter sua independência financeira e gerir sua 
terra. Almejava igualdade e liberdade, assim com a desfrutada pelos homens. Nesse sentido Miguel corrobora:

No entanto, a igualdade reivindicada vai ser entendida como a busca pela inserção numa universalidade que não é neutra já está preenchida com as características do "masculino". As mulheres querem ser cidadãs, mas a própria ideia de cidadania foi construída tomando como base a posição do homem (e, em particular do homem branco e proprietário) numa sociedade marcada por desigualdades de gênero, bem como de raça e classe. (MIGUEL, 2014, p. 64).

Naquela região, Sul Africana, independentemente do fato de serem brancas ou negras as mulheres estavam subordinadas aos homens, fossem eles brancos ou negros, existindo apenas formas diferentes de dominação. Portanto, Lucy, até esse momento da narrativa, tem uma posição favorável, conseguindo manter sua casa sem necessariamente ter que seguir os padrões culturais e sociais da região.

\begin{abstract}
Às sete, com o amanhecer tocando as montanhas e os cachorros começando a se agitar, o trabalho está terminado. A kombi está carregada com caixas de flores, sacos de batata, cebola, repolho. Lucy vai dirigindo, Petrus fica atrás. O aquecedor não funciona; com as janelas embaçadas ela pega a estrada de Grahamstown. Ele vai ao seu lado, comendo os sanduíches que ela fez. Sente o nariz pingando; espera que ela não note. Então: uma nova aventura. Sua filha, que um dia ele costumava levar para a escola e para as aulas de balé, ao circo e ao rinque de patinação, agora o leva a passear, mostrando-lhe a vida, mostrando-lhe este outro mundo, desconhecido [...] Muitos clientes de Lucy a conhecem pelo nome: senhoras de meia-idade, a maior parte, com um toque de altivez no trato com ela, como se o sucesso dela lhes pertencesse também. (COETZEE, 1999, p.67)
\end{abstract}

A mulher lutou, luta, e lutará para conquistar autonomia e atenuar as disparidades ocorridas entre elas e os homens nas sociedades que vão se construindo e reconstruindo ao longo dos anos. Apesar de todas as mudanças ocorridas como a participação no mercado de trabalho, direito ao voto, participação na política e direito à educação, muitas mulheres ainda sofrem com o sistema patriarcal, com a falta de autonomia e a violência sexual, principalmente em países em desenvolvimento e em áreas de conflito. Nesse aspecto Biroli reforça:

A violência contra a mulher pode ser entendida como uma prática social, e não individual, sistêmica porque dirigida a membros de um grupo simplesmente porque eles são membros daquele grupo. $\mathrm{O}$ estupro seria nada mais, nada menos que um processo consciente de intimidação pelo qual todos os homens mantêm todas as mulheres num estado de medo (BIROLI, 2014, p. 113).

Em países que viveram conflitos, invasões e disputas políticas e inter-raciais a mulher como podemos ver na constituição das civilizações e pela própria história da humanidade é a parte mais oprimida, território simbólico, demarcado por abusos e violências.

Singularmente no contexto pós-colonial, onde os nativos da África do Sul estavam tentando recuperar sua identidade, se libertar da opressão, discriminação e da violência 
vivenciadas por anos de dominação e segregação, o negro revida todas as mazelas como descreve o romance Desonra de Coetzee, o acontecimento é descrito de forma brutal, narrando o momento em que três homens invadem a casa de Lucy, filha do protagonista David.

\begin{abstract}
Recebe um golpe no alto da cabeça. Tem tempo de pensar, Se estou consciente então tudo bem, antes de sentir os membros se liquefazerem e cair. [...] Sua filha está nas mãos de estranhos. Dentro de um minuto, de uma hora, será tarde demais; seja o que for, o que está acontecendo com ela ficará gravado em pedra, pertencerá ao passado. Mas agora ainda não é tarde demais. Agora ele tem de fazer alguma coisa. [...] Ele tenta forçar a saída, passa pelo homem, mascai pesadamente. Levou uma rasteira: eles devem praticar isso jogando futebol. Enquanto está ali caído, é ensopado com um líquido dos pés à cabeça. Os olhos ardem, ele tenta esfregar. Reconhece o cheiro: metanol. Tenta se levantar, é empurrado de volta para o lavabo. Um riscar de fósforo e vê-se imediatamente envolto em frias chamas azuis. [...] David, quando as pessoas perguntarem, você se importaria de contar só a sua parte, só o que aconteceu com você? (COETZEE, 1999, p. 91).
\end{abstract}

Para Fanon (1990, p. 74) a imobilidade colonial termina por um ato de consciência que abre a porta à violência, uma força purificadora. Ocorre nesse momento, um desejo de provocar o medo, angústia e o desamparo que outrora foram sentidos pelos colonizados. Pois o processo de descolonização foi tão violento quanto o de colonização. "A violência do regime colonial e a contra violência do nativo se equilibram e respondem a si próprias numa extraordinária homogeneidade recíproca. Esse reino de violência será tão terrível quanto foi a sua implantação pela metrópole" (FANON, 1990, p. 69).

Esta afirmativa aponta para acontecimentos ocorridos no romance, três homens negros invadiram a casa de Lucy, violentaram sua filha e roubaram suas coisas. Este fato terrível descrito no romance foi uma forma de responder aos brancos todas as violências, humilhações, subordinações e mazelas que os colonizadores os fizeram passar sem acesso as mesmas possibilidades e oportunidades trabalhistas, sem educação igualitária e sem dignidade. A revanche em relação à violência histórica, a mudança de panorama social representou a alegoria do desejo de provocar o medo.

O protagonista David ficou perplexo com a violência, barbárie e animalidade praticadas contra eles, mas compreende que o contexto agora é outro. "É assim que se deve ver a vida neste país: em seu aspecto esquemático. Senão se enlouquece. Carros, sapatos; mulheres também. Deve haver no sistema algum nicho para as mulheres e para o que acontece com elas" (COETZEE, 1999, p. 91).

As polêmicas, contradições e conflitos entre brancos e negros relatados na obra são baseados nas assimetrias de gênero, raça e sexualidade ressaltando verdadeiras disputas pelo poder. Pois os colonizados e excluídos socialmente lutavam por direito à igualdade tanto em 
relação à classe como em relação ao gênero. O sujeito objeto de antes, dominado, subjugado e discriminado estava reivindicando seu lugar na sociedade.

Agora eles tinham a autoridade e o poder, mesmo que fosse por meio da "força bruta". No enredo aos poucos vão se realocando os sujeitos e quem estava na condição de subalterno, agora ocupa uma posição de superioridade, e quem antes dominava, agora estava aviltado.

A literatura pós-colonial, através de obras metaficcionais e ficcionais tem o poder de retratar, representar e levar a compreensão da natureza humana, e suas mais adversas situações. Nesse aspecto "A literatura não deve apenas se opor ao Império, mas cercá-lo, sufocá-lo, envergonhá-lo, expô-lo ao ridículo" (ROY, 2003, p. 112).

Dessa forma, é necessário lançarmos um olhar sobre a história, procurando pontos de cisão, pontos nebulosos de um tempo e revisitar sua origem para enfim, compreender suas causas e consequências. Incursão realizada criticamente pelo escritor Coetzee, por meio da sua personagem Lucy que representa a junção de espaços e tempos, elemento pacificador e “espaço de integração". O corpo de Lucy é território simbólico, cobrado historicamente pelos erros do passado e carrega a semente de um futuro pacífico.

\subsection{A mulher negra: explorada e objetificada}

No romance Desonra de Coetzee, a mulher negra não europeia luta pela igualdade econômica, social e de gênero. Opondo-se à objetificação de seu corpo, luta contra os anos de exploração sob o domínio do homem branco rompendo o silêncio como é narrado em duas situações distintas: a primeira se apresenta quando a prostituta Soraya se contrapõe à dominação de David Lurrie, homem branco pertencente a classe dominante. A segunda ocorre com a personagem Melanie uma aluna que posteriormente foi estuprada por David, colonizador reescrito na história e o denuncia. Ressaltando que a sociedade tinha mudado e que "O colonizado fala quando se transforma num ser politicamente consciente que enfrenta o opressor com antagonismo sem cessar" (BONNICI, 2012, p.26).

Soraya tem uma relação comercial com David, um professor solitário de cinquenta e dois anos. Encontros marcados semanalmente sempre as quintas.

A mulher é extremamente sensual, bonita e aparentemente submissa às vontades de seu cliente. Pois Soraya era vista como um Oasis enchia de vida o deserto da maturidade, que David atravessava. Em um de seus encontros semanais, Soraya estava com batom vermelho e muita sombra nos olhos. "Como não gostava de maquiagem pegajosa, ele pediu que tirasse tudo. Ela obedeceu, e nunca mais usou. Uma aluna rápida, amável, maleável” (COETZEE, 1999, p.04). "Simbolicamente voltadas à resignação e à discrição, as mulheres só podem 
exercer algum poder voltando contra o forte a sua própria força, ou aceitando se apagar, ou, pelo menos, negar um poder que elas só podem exercer por procuração. (BOURDIEU, 2002, p.43) Observa-se por um período da narrativa o domínio de David, que promove o apagamento de Soraya.

Tudo estava bem, até que David a encontra por acaso na rua e começa a invadir seu espaço, segui-la e telefonar para sua casa. Ela disse para ele não ligar mais e respeitar a sua decisão. Demonstrando consciência de sua situação Soraya se libertou da opressão que estava sofrendo, mostrando uma mudança de comportamento, autonomia, frente ao domínio eurocêntrico, representado no romance pelo Professor David.

Logo em seguida ele se envolve com Melanie, uma aluna negra. Invade sua vida, insiste para sair com ela, vai até seu apartamento, domina Melanie, e ela não consegue desvencilhar-se dele. "Estupro não, não exatamente, mas indesejado mesmo assim, profundamente indesejado. Como se ela tivesse resolvido ficar mole, morrer por dentro enquanto aquilo durava." (COETZEE, 1999, p. 27). Melanie se sente invadida, explorada aviltada, tenta fugir das persistentes investidas do professor inutilmente. Sentia-se pressionada e então resolveu denunciá-lo para a comissão da Universidade que decidi julgá-lo. David não assume e muito menos se desculpa pelo seu ato, então perde seu emprego. Esse fato pode ser explicado como:

A negação da realidade do estupro decorre amplamente do fato de que a validade do consentimento dos indivíduos é distintamente considerada se são homens ou mulheres-e isso se agrava quando se leva em consideração a posição de classe dessas mulheres e possíveis "desvios" em sua vida sexual em relação aos códigos morais predominantes. (BIROLI, 2014, p. 112).

O fato de David ter perdido o emprego, prestígio e sua honra, é visto como uma justiça histórica, pelos anos de exploração e objetificação que mulheres negras sofreram no período colonial e ainda pós-colonial, pois são barreiras sociais e políticas difíceis de serem rompidas. A voz de Soraya e Melanie demonstra uma nova perspectiva de futuro para a mulher negra na África do Sul uma espécie de reparação histórica e recuperação da sua voz através da resistência.

\section{Conclusão}

Desonra, o romance de Coetzee faz parte da literatura pós-colonial e retrata a mudança de posições sofridas pelo homem branco, que outrora dominava em relação ao negro escravizado, subjugado e discriminado ao longo da história colonial. Além de discutir como 
as mulheres na África do Sul foram as mais impactadas com a violência inter-racial, principalmente as negras.

A forma como Coetzee aborda essas questões da segregação racial e a submissão feminina nos leva a refletir, entender e questionar alguns pontos obscuros da história. Ressaltando que a literatura também tem seu papel, segundo Bhabha (2003, p.34) "O crítico deve tentar apreender totalmente e assumir a responsabilidade pelos passados não ditos, não representados, que assombram o presente histórico".

Os efeitos da segregação racial ainda não foram reparados e a discriminação sofrida pelos sul-africanos ainda persisti, pois, esses fatos têm raízes muito mais profundas e dolorosas do que podemos supor. Pode se constatar que o romance de Coetzee, descreveu mudanças e deslocamentos sociais, onde aos poucos o negro está se libertando da sujeição e a mulher negra antes objetificada, rompe a estrutura de dominação e exploração. Contudo, Coetzee sugere um novo caminho para a segregação racial, através da reparação histórica e da união das raças por meio do filho de Lucy, vislumbra a esperança de um futuro pacífico por meio da reconciliação.

\section{Referências}

BEAUVOIR. Simone de. O segundo sexo. Trad. Sérgio Miliet. Rio de Janeiro: Nova. 2000.

BERND, Zilá. Literatura e identidade nacional. Porto Alegre: UFRGS, 2003.

BHABHA, Homi. O local da cultura. Trad. Myriam Ávila, Eliana Lourenço de Lima Reis, Gláucia Renata Gonçalves. Belo Horizonte: UFMG, 2003.

BONNICI, Thomas (org). Resistência e intervenção nas literaturas pós-coloniais. Maringá: Eduem, 2009.

BONNICI, Tomas. O pós-colonialismo e a literatura: Estratégias de leitura. $2^{\circ}$ ed. Maringá: Eduem, 2012

BONNICI, Thomas, Pós-colonialismo e representação feminina na literatura pós-colonial em inglês. Acta Scientiarum. Human and Social Sciences. V. 28 N. 1, Maringá: Eduem, 2006. Acessado em 29 de julho de 2018. Disponível em: http://www.periodicos.uem.br/ojs/index.php/ActaSciHumanSocSci/article/view/178

BOSI, Alfredo. Literatura e resistência. São Paulo: Companhia das Letras, 2002.

BOURDIEU, P. A dominação masculina. Rio de Janeiro: Bertrand Brasil, 2002.

BRUSCHINI, C. (Org.). Uma questão de gênero. Rio de Janeiro: Rosa dos Tempos, 1992. p. $183-215$.

BUTLER, Judith P. Problemas de gênero: Feminismo e subversão da identidade. Tradução, Renato Aguiar. Rio de Janeiro. Ed. Brasileira, 2003.

CINTRA, Antônio O. As comissões de verdade e reconciliação: o caso da África do Sul. Brasília: Biblioteca digital da Câmara dos deputados, 2001. 
COETZEE, J. M. Desonra. Trad. José Rubens Siqueira. São Paulo: Companhia das Letras, 1999.

DU PLESSIS, R. B. Writing beyond the ending: narrative Strategies of 20th Century Women Writers. Bloomington: Indiana UP, 1985.

DUBOW, S. Scientific racism in modern South Africa. New York: Cambridge University, 1995.

FANON, F. Black Skin. White Masks. London: Marc Gibbon and Jey. 1968.

FANON, F. Os condenados da terra. Rio de Janeiro: Civilização Brasileira, 1968.

FANON, F. The wretched of the earth. Harmondsworth: Penguin, 1961.

MIGUEL, Luis Felipe. Feminismo e política: Uma introdução/Luis Felipe Miguel, Flávia Biroli. 1.ed. São Paulo: Boitempo, 2014.

ROY, A. War talk. Boston: South End, 2003.

SAFFIOTI, H.I. B. Rearticulando gênero e classe social. In: OLVEIRA, A.; BRUSCINI, C. (Org.). Uma questão de gênero. Rio de Janeiro: Rosa dos Tempos; São Paulo: Fundação Carlos Chagas, 1992. p. 183-215. 